\title{
Associations between self-efficacy, bullying and health-related quality of life in a school sample of adolescents: a cross-sectional study
}

\author{
Kristin Haraldstad ${ }^{1 *}$ (D) Lisbeth G. Kvarme ${ }^{2}$, Knut-Andreas Christophersen ${ }^{3}$ and Sølvi Helseth ${ }^{1,2}$
}

\begin{abstract}
Background: To better understand health-related quality of life (HRQOL) in adolescents, it is important to gain knowledge about factors associated with HRQOL. Being involved in bullying is a significant threat to health, and social and psychological well-being; further, such problems can last into adulthood. The aim of this study was to explore the role of general self-efficacy (GSE) and bullying in relation to HRQOL. We specifically sought to study the prevalence of bullying, as well as the associations between both bullying and self-efficacy and HRQOL in a sample of adolescents.

Methods: This was a cross-sectional study of 723 adolescents (12-18 years) attending schools selected using randomized cluster sampling. HRQOL was measured using the KIDSCREEN-52, self-efficacy was measured with the GSE scale, and bullying was measured using the two global questions from the Olweus bullying questionnaire. Multiple regression analyses were performed to explore how being bullied, bullying, and GSE were associated with variations in self-reported HRQOL.

Results: Of the 723 adolescents, 13\% reported being bullied; there were no gender differences within this finding. However, more boys than girls reported that they had bullied others. Both being bullied, and bullying others, were associated with lower HRQOL; however, being bullied was associated with the lowest scores. Higher self-efficacy was associated with better HRQOL. Self-efficacy contributed significantly to predicting variation in HRQOL.

Conclusions: Being involved in bullying, as a victim or a bully, is associated with lower HRQOL. The association between GSE and HRQOL indicates that self-efficacy might be a resource for increasing HRQOL among adolescents. Our findings highlight the importance of targeting self-efficacy beliefs as an intervention strategy to improve GSE and $\mathrm{HRQOL}$ in adolescents involved in bullying.
\end{abstract}

Keywords: Health-related quality of life, Adolescents, Self-efficacy, Bullying

\section{Background}

The concept of health-related quality of life (HRQOL) as a general outcome is of growing interest in the field of public health and is acknowledged as a useful measure of health and well-being in both adult and adolescents populations $[1,2]$. HRQOL is a multidimensional construct and includes measures of physical symptoms, functional status, psychological and social functioning [3]. The

\footnotetext{
* Correspondence: kristin.haraldstad@uia.no

${ }^{1}$ Faculty of Health- and Sport Sciences, University of Agder, P.O box 422, 4604 Kristiansand, Norway

Full list of author information is available at the end of the article
}

multidimensionality of health-related quality of life measures (HRQOL) gives researchers and clinicians information about the impact of a health condition, or the effect of various interventions on different aspects of HRQOL, and serves as a framework for identifying and developing strategies to promote HRQOL [2].

To enhance well-being among adolescents, and to better understand HRQOL in adolescents, it is important to study factors associated with HRQOL. HRQOL is a positive phenomenon and is therefore particularly relevant within the health promotion perspective, insofar as it focuses on resources rather than problems $[4,5]$. The

(c) The Author(s). 2019 Open Access This article is distributed under the terms of the Creative Commons Attribution 4.0 International License (http://creativecommons.org/licenses/by/4.0/), which permits unrestricted use, distribution, and reproduction in any medium, provided you give appropriate credit to the original author(s) and the source, provide a link to the Creative Commons license, and indicate if changes were made. The Creative Commons Public Domain Dedication waiver (http://creativecommons.org/publicdomain/zero/1.0/) applies to the data made available in this article, unless otherwise stated. 
concept of self-efficacy has been suggested as one such focus. Self-efficacy is a central part of Bandura's [6, 7] social cognitive theory. Self-efficacy includes individuals' thoughts about their successes and failures, and their perceptions of feedback they have received. Previous studies have shown that a high degree of self-efficacy is related to higher self-belief [8], and that self-efficacy is one of the most important factors contributing to behavior change [9]. This concept was expanded upon by Schwarzer and Renner, who developed the term general self-efficacy (GSE), which is used herein [10].

Positive associations have been reported between GSE measures and HRQOL among adults, but few studies have examined this in children or adolescents [5]. Among those that have, Kvarme and colleagues [5] reported a strong, positive relationship between GSE and HRQOL among schoolchildren, indicating that GSE might be a resource for increasing HRQOL in this population.

Though bullying is a factor known to negatively affect adolescents' health and well-being, few studies have regarded the associations between bullying and HRQOL. A relatively small number of studies do show that being bullied by peers, and bullying others, are both significantly related to lower HRQOL levels [5, 11-17]. The majority of these studies have shown that being involved in bullying is related to lower HRQOL, particularly on scales measuring social and mental health $[11,17]$.

In recent years, awareness of bullying among adolescents has increased and is now widely recognized as one of the most significant public health problems within this age group [4]. In a systematic review, a mean prevalence of bullying was reported to be $35 \%$ and victimization was found in $36 \%$ of adolescents aged $12-$ 18 years [18]. However, the prevalence of bullying differs across studies [5, 19-21], with some studies showing a prevalence in Norway and the other Scandinavian countries that is slightly lower compared with most other countries [22-24].

Several studies have shown that being bullied is a significant threat to both short- and long-term health, as well as social and psychological well-being. Those who are bullied during childhood are more likely to report depression, social anxiety low self-esteem, and academic problems later in life [11, 25-29]. In addition, bullies themselves can have long-term health challenges, including a high prevalence of antisocial problems, physical health problems, and higher use of health support [30-34].

The most common definition of bullying is that a person is bullied "when she or he is exposed to negative actions from one or more persons recurrently over time" [35]. A negative action is when a person intentionally inflicts, or attempts to inflict, discomfort or injury upon another person. Bullying occurs in a relationship in which there is an imbalance of power or strength $[36,37]$.
Because bullying is complex, it is important to study this problem from different perspectives. Most previous studies have explored the negative health consequences related to being bullied. From a health promotion perspective, it is important to study how this phenomenon is related to adolescents' HRQOL [38]. Although much of the research in this area has focused on understanding bullying and its health consequences, far less is known about the associations between bullying, selfefficacy, and HRQOL in adolescents.

The aim of this study was therefore to explore the roles of self-efficacy and bullying in relation to HRQOL. We specifically sought to determine the prevalence of bullying and examine the associations between both bullying and self-efficacy and HRQOL in a sample of adolescents.

\section{Methods}

These cross-sectional analyses are part of a larger study of HRQOL among Norwegian adolescents in an eastern region of Norway with a population of approximately 1.7 million, among which the child/adolescent population is approximately 230,000. For this study, Statistics Norway drew a cluster sample of 19 randomly selected schools using the criteria: geographic spread, rural and urban districts, and small and large schools. The schools were each sent a letter of invitation, which was followed by a telephone call. The seven schools that did not elect to participate were substituted with other schools selected based on the same criteria. From the final sample of 19 schools, classes that covered grades 7 and 9 in elementary schools, and grades 1 and 3 in secondary schools were selected; the age range included was thus $12-18$ years.

After school enrollment in the study, the adolescent students were invited to participate. They and their teachers were also given verbal and written information at school by the investigator 1 week before the study took place. They received standard information about the study and a written consent form for the adolescents' parents to read and sign. The self-report questionnaires were administered and completed in the classrooms during school time.

The study was reviewed and approved by the Regional Research Ethics Committee of Norway (REK. Sør S-06143).

\section{Instruments}

\section{Demographic variables}

The first part of the questionnaire recorded demographic details for nationality, gender, date of birth, cohabitant status, and parental marital status.

\section{Self-efficacy}

Self-efficacy was measured with a GSE scale ranging from 1 to 4 [31]. The scale was designed to measure a general sense of perceived self-efficacy and aimed to 
predict an ability to cope with daily demands and adaptation after a stressful experience. A revised five-item version of the questionnaire, designed for the general population aged 12 years or older, was used for this study [39].

A questionnaire item example is, "I always manage to solve difficult problems if I try hard enough." The instrument has a four-point scale where $1=$ "completely wrong" and $4=$ "completely right." Higher scores indicate higher levels of GSE. This scale has been shown reliable and valid, with a Cronbach's $\alpha$ between 0.75 and $0.90[5,10,40]$.

\section{Bullying}

Bullying was measured using two global questions [26, 35 ] that were developed in Norway and have been used in previous studies [29, 41]. Bullying herein was defined according to the definition by Olweus [37]. The two questions address how often the child had been a victim of bullying or has bullied others during the previous 3 months. For example, "How often have you been bullied?" and "How often have you bullied others?" Both questions were answered using a five-point scale where $1=$ "never", 2 = "only once or twice", 3 = "two or three times a month", $4=$ "about once a week", and $5=$ "several times a week." In the analyses presented here, the two bullying variables were dichotomized as never or only once or twice or more.

\section{Health-related quality of life}

HRQOL was measured with the Norwegian version of the KIDSCREEN-52 [42]. KIDSCREEN-52 is a generic questionnaire developed to evaluate HRQOL in children and adolescents and includes dimensions such as family, social relationships, physical functioning, psychological well-being, self-perception, school, autonomy, and financial resources $[2,43]$. The instrument provides a comprehensive indication of health and well-being in children and adolescents [44]. The instrument includes 52 items, each of which is rated on a five-point Likert scale referring to the last week. The scale indicates either the frequency of certain behaviors or feelings (where $1=$ "never", 2 = "seldom", 3 = "sometimes", 4= "often", and $5=$ "always") or the intensity of an attitude (where 1 = "not at all", $2=$ "slightly,", $3=$ "moderately", $4=$ "very", and $5=$ "extremely"). Though these 52 items are usually divided into 10 dimensions, we used only nine of these dimensions after removing the three questions about bullying. The following dimensions were used: (1) physical well-being (five items); (2) psychological well-being (six items); (3) moods and emotions (seven items); (4) self-perception (five items); (5) autonomy (five items); (6) parental relations (six items); (7) financial resources (three items); (8) social support and peers (six items); (9) school environment (six items). Example questions from each dimension are: "When you think of the last week... (1) ...have you felt fit and well?"; (2) "...have you felt satisfied with your life?”; (3) “...have you felt lonely?”; (4) "...have you been happy with the way you are?"; (5) “... have you had enough time for yourself?"; (6) "...have you felt loved by your parents?"; (7) "...have you had enough money to do things with your friends?"; (8) “...have you had fun with your friends?"; and (9) "...have you enjoyed going to school?" The scale was reversed for negatively worded items and missing values were substituted with the mean of the nonmissing items. However, according to the KIDSCREEN manual [45], no score was computed if more than one item per scale was missing and the three-item scales required that all items be completed. The dimension score was then transformed linearly to a $0-100$-point scale, with 100 and 0 indicating the best and worst HRQOL, respectively. The KIDSCREEN-52 tool has been translated into several languages and its cross-cultural comparability and psychometric properties have been found satisfactory in different language versions. The Norwegian child version has shown satisfactory validity and reliability [42].

\section{Statistical analysis}

The analyses were conducted using IBM SPSS Statistics (version 24.0; IBM Corp. Armonk, NY, USA). Descriptive statistics are presented for all dependent and independent variables. Cronbach's $\alpha$ was computed to assess the reliability for each HRQOL dimension and self-efficacy. Pearson's product moment correlation was used to examine the relationships between each of the nine dimensions of the KIDSCREEN-52 scale and independent variables. To examine how each independent variablebeing bullied, bullying, and self-efficacy were associated with HRQOL, multiple linear regression analyses were performed with each of the nine KIDSCREEN subscales as dependent variables. For each HRQOL dimension, four regression models were estimated.

In the first model, the theoretically most important independent variable, self-efficacy, was the only independent variable. In the second model, the variables bullied, and bullying were added to the model as independent variables. In the third model, interaction between selfefficacy and respectively bullying and bullying were added, and in the fourth model, gender and age were also included as control variables.

The models were analyzed, using standardized independent variables. Then, the regression coefficients could be compared and, in addition, the importance of multicollinearity due to interaction was reduced.

The most important information lies in the regression coefficients, the change from one model to the next in regression coefficients and in $\mathrm{R}^{2}$-adjusted. While $\mathrm{R}^{2}$-unadjusted 
always increase when a new variable is added to a model, $\mathrm{R}^{2}$-adjusted can also decrease indicating that the model may be miss-specified having at least one irrelevant variable or an inadequate functional form.

\section{Results}

Table 1 shows the sample characteristics for all dependent and independent variables. The age range was 12-18 years, with a mean of 14.6 years. After excluding adolescents with missing values, the sample eligible for inclusion in analyses was $N=723$ (54\% girls), response rate $74 \%$. Of the participating adolescents, $13 \%$ reported being bullied within the previous 3 months (Table 1). In addition, 13\% of the sample ( $9.4 \%$ girls, $17.5 \%$ boys) reported that they had bullied others.

All nine HRQOL dimensions had skewness values of \pm 1.5 and eight had kurtosis values of \pm 1 (Table 2), indicating that these variables are approximately normally distributed.

Results from the correlations analysis (Table 2) show that HRQOL decreased significantly with age and that girls had lower HRQOL compared with boys on most of the KIDSCREEN subscales, meaning that being a boy and being among the youngest in the age group were both positively associated with HRQOL. Both being bullied, and bullying others, were negatively correlated with the HRQOL dimensions. Moreover, higher GSE scores were associated with better HRQOL across all dimensions.

Cronbach's $\alpha$ values for the HRQOL scales were sufficient, from .82 (scale 4) to .89 (scale 7).

Multiple linear regression analyses were performed with each of the nine KIDSCREEN subscales as dependent variables (Table 3 ). In model 1 self-efficacy was included in the model and had a significant $(p<.01)$ effect on all nine HRQOL scales, but the greatest effect on scale 1 . Moreover, in model 2, the variables being bullied, and bullying were included. Being bullied had a significant effect on four scales (scale 2, 3, 7, and 8) and bullying on just one (scale 9). These three variables predicted from $7.9 \%$ (scale 7 ) to $12.8 \%$ (scale 4) of the variance.

In model 3, two interaction terms were entered, one between self-efficacy and being bullied, and one between self-efficacy and bullying. The interaction between selfefficacy and bullying is significant $(p<.05)$ on three scales $(2,4$ and 9$)$ in model 3 . When controlled for gender and age in model 4, only the coefficient for scale 9 remains significant. In addition, the change in $\mathrm{R}^{2}$-adjusted decreases for scale 3,7 and 8 from model 2 to model 3. Therefore, the main conclusion for model 3 is that the impact from the interaction terms is very weak.

In model 4 gender and age were included as control variables in addition to the three variables and the interaction terms. Self-efficacy still had significant $(p<.01)$ effects on all scales and being bullied on five (scales 2, 3, 5,7 , and 8) and bullying on two (scale 6 and 9). Gender and age increased the predicted variance. The predicted variance now varied from $11.5 \%$ (scale 6) to $26.7 \%$ (scale 4). The lowest change in predicted variance was for scale 7 and the highest was for scale 4 .

\section{Discussion}

The purpose of this study was to describe the prevalence of bullying and associations between both bullying and GSE and HRQOL in a sample of adolescents aged 1218 years. A main finding was that both being bullied, and bullying others were associated with lower HRQOL, and that a higher GSE was associated with better

Table 1 Descriptive statistics for all variables, ks01-09 are 9 kidscreen dimensions, $N=723$

\begin{tabular}{|c|c|c|c|c|c|c|c|}
\hline Variables & Min & Max & Mean & SD & Skewness & Kurtosis & Alpha \\
\hline ks01 (Phys well-being) & 0 & 100 & 65.00 & 21.25 & -0.30 & -0.65 & .84 \\
\hline ks02 (Psych well-being) & 8 & 100 & 75.78 & 18.25 & -0.94 & 0.69 & .89 \\
\hline ks03 (Moods/emotion) & 18 & 100 & 81.42 & 14.71 & -1.39 & 2.22 & .86 \\
\hline ks04 (Self-perception) & 0 & 100 & 70.19 & 20.78 & -0.64 & -0.25 & .82 \\
\hline ks05 (Autonomy) & 0 & 100 & 68.51 & 20.73 & -0.58 & -0.14 & .85 \\
\hline ks06 (Parents-relationship) & 8 & 100 & 75.75 & 19.04 & -0.80 & 0.23 & .88 \\
\hline ks07 (Financial resources) & 0 & 100 & 78.53 & 23.28 & -1.13 & 0.75 & .89 \\
\hline ks08 (Peers and social supp) & 21 & 100 & 73.14 & 17.07 & -0.47 & -0.35 & .83 \\
\hline ks09 (School environment) & 0 & 100 & 62.39 & 19.21 & -0.21 & -0.24 & .87 \\
\hline Gender (girls $=0$, boys $=1$ ) & 0 & 1 & 0.46 & 0.50 & 0.17 & -1.98 & \\
\hline Age & 12 & 18 & 14.6 & 2.15 & 0.31 & -1.22 & \\
\hline Bullied & 0 & 1 & 0.13 & 0.34 & 2.15 & 2.64 & \\
\hline Bullying & 0 & 1 & 0.13 & 0.34 & 2.19 & 2.79 & \\
\hline Self efficacy & 1.20 & 4.00 & 3.07 & 0.60 & -0.31 & -0.38 & \\
\hline
\end{tabular}


Table 2 Correlations. Pearson's $r$ for all variables, $N=723$

\begin{tabular}{|c|c|c|c|c|c|c|c|c|c|c|c|c|c|}
\hline & ks01 & ks02 & ks03 & ks04 & ks05 & ks06 & ks07 & ks08 & ks09 & Gen & Age & Bulli & Bully \\
\hline ks02 (Psych. well-being) & .51 & & & & & & & & & & & & \\
\hline ks03 (Moods/emotions) & .38 & .66 & & & & & & & & & & & \\
\hline ks04 (Self-perception) & .39 & .49 & .54 & & & & & & & & & & \\
\hline ks05 (Autonomy) & .44 & .51 & .40 & .42 & & & & & & & & & \\
\hline ks06 (Parents relationship) & .35 & .59 & .54 & .48 & .44 & & & & & & & & \\
\hline ks07 (Financial resources) & .28 & .30 & .34 & .31 & .29 & .40 & & & & & & & \\
\hline ks08 (Peers \& social support) & .31 & .49 & .32 & .20 & .44 & .39 & .24 & & & & & & \\
\hline ks09 (School environment) & .40 & .54 & .44 & .39 & .40 & .52 & .36 & .34 & & & & & \\
\hline Gender & .16 & .09 & .14 & .34 & .15 & .06 & .06 & -.12 & -.06 & & & & \\
\hline Age & -.22 & -.19 & -.16 & -.22 & -.31 & -.15 & .01 & -.09 & -.27 & -.02 & & & \\
\hline Bullied & -.07 & -.19 & -.20 & -.14 & -.13 & -.14 & -.22 & -.23 & -.14 & .01 & -.11 & & \\
\hline Bullying & -.03 & -.08 & -.11 & -.06 & -.03 & -.11 & -.11 & -.08 & -.21 & .12 & -.06 & .30 & \\
\hline Self- efficacy & .35 & .32 & .29 & .35 & .27 & .28 & .31 & .21 & .26 & .21 & .04 & -.17 & .00 \\
\hline
\end{tabular}

HRQOL. Self-efficacy contributed significantly to predicting variation in all HRQOL dimensions among this sample.

We found that $13 \%$ of the sample reported having been bullied during the previous 3 months, and that there were no gender differences within this finding. However, more boys than girls reported that they had bullied others. In a recent review, $20-25 \%$ of adolescents were involved in bullying as victims, perpetrators, or both [46]. In a meta-analysis on bullying prevalence, a mean prevalence of $35 \%$ for traditional bullying (both perpetration and victimization roles) and $15 \%$ for cyberbullying involvement were estimated [18]. The results of this meta-analysis showed a higher prevalence than detected in our study. Previous research has also demonstrated that the Scandinavian countries report a lower prevalence of bullying compared with other countries [25]. Possible explanations of this prevalence are strong anti-bullying policies, and focus on school-based antibullying programs, as for instance Olweus -programmes, in in the Nordic countries, most in Sweden and Norway $[22,23,37,47]$. However, the prevalence rates of bullying vary between studies, partly because of differences in methods and questionnaires, which makes it difficult to compare results [48].

HRQOL is one way to study children's subjective perspectives on bullying and the impact it has on their lives, in addition to the known negative impacts on their health and well-being [13, 17, 31]. The results of our analysis show that being involved in bullying-both as a bully and as a victim-is negatively associated with HRQOL. Being bullied was most strongly associated with HRQOL on the dimensions of "social support and peers", "financial resources", "autonomy", "moods and emotions", and "psychological well-being." The dimension "social support and peers" had the lowest correlation value; this dimension examines aspects related to relationships with friends, the extent to which the person experiences positive group feelings, and support by his/her peers [2]. Relationships with friends are important at this age, and problematic peer relations are associated with psychological and social problems during adolescence [49]. Previous research has found that having friends and feeling peer support are positive and can protect children from bullying, while social support may be a buffer against bullying $[21,27,46,50]$.

Our results indicate that victims of bullying have lower HRQOL. They are generally less happy, may be less satisfied with their relationships with friends, have a less positive perception of themselves, are less positive about going to school, and are less satisfied with the financial resources in their family. This is in accordance with previous research; in a study from 11 European countries, being bullied was associated with significantly poorer HRQOL on all dimensions measured with the KIDSCREEN-52. The strongest associations were with the dimension "moods and emotions" and the weakest were with "physical well-being" [43]. A Swedish study also found that adolescents who reported being bullied had lower scores on all HRQOL subscales, measured with the SF-36 [17]. Findings from an Australian study show that being bullied is associated with significantly poorer psychosocial QoL; however, in that study, the physical dimensions were not related to being bullied [11].

In our study, it is notable that being involved with bullying-either as a bully or as a victim-had a negative association with HRQOL, although being a victim of bullying had the strongest association. However, bullying others had the strongest negative association with the two behaviors in the subscale "school environment." A 


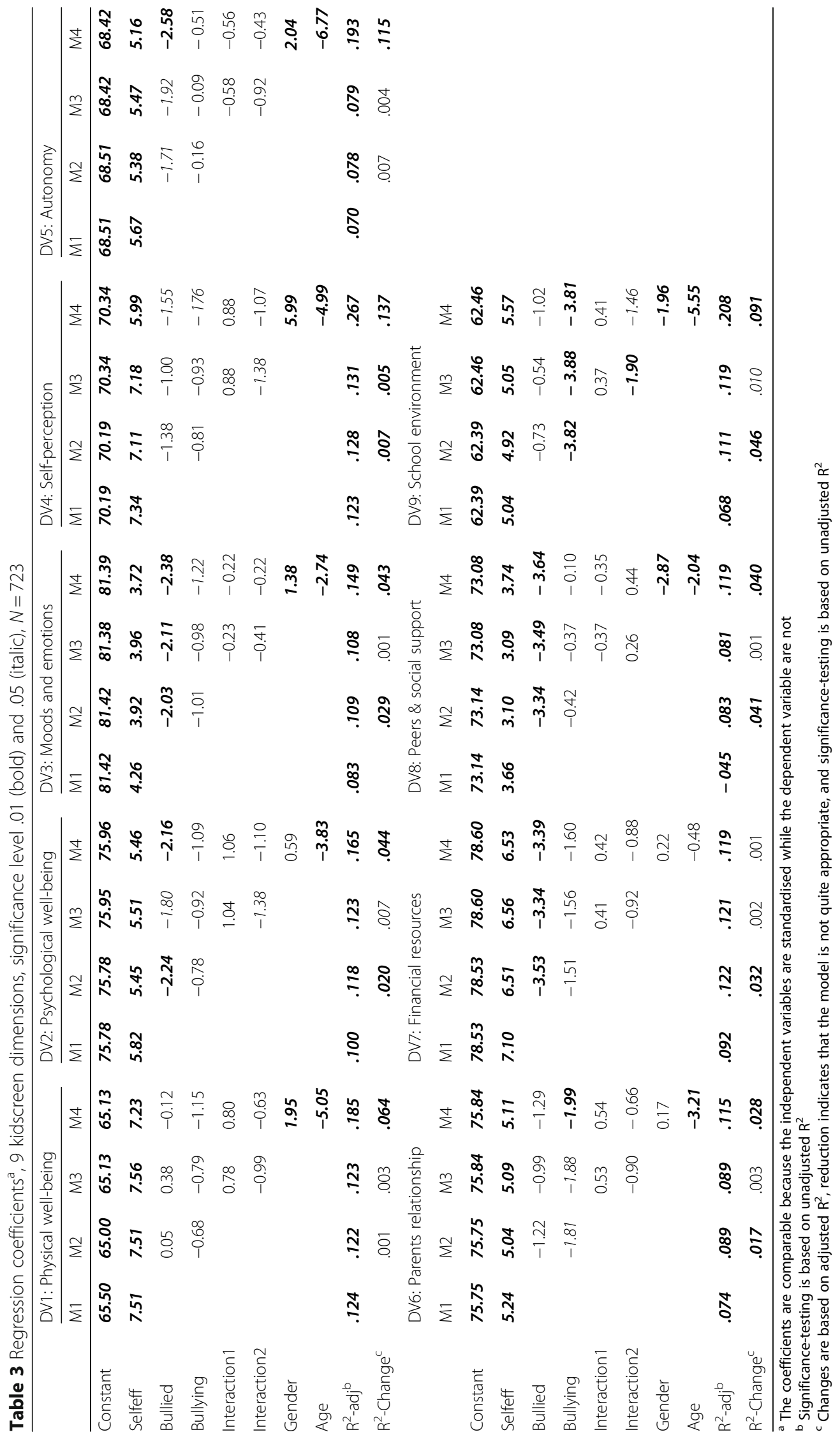


lower score on this dimension indicates that the individual has negative feelings about school and is not doing well at school [43]. Few studies have investigated both bullying and being bullied in relation to HRQOL, yet our results are consistent with a study from Sweden showing that being involved in bullying, as a bully or victim, was associated with lower HRQOL [17]. One possible explanation for this is the stress experienced from being involved with bullying, in either role [23].

Interestingly, in our study, being bullied was associated with lower HRQOL on the dimension "financial resources." This dimension examines whether the individual is satisfied with his/her financial resources and takes part in activities with friends [43,51]. It is well known that high socioeconomic groups do better on a range of health outcomes, and previous studies have shown that schoolchildren from single-parent families and those with lower socioeconomic status had the highest odds for emotional symptoms and were less resilient to bullying [52].

Our findings are consistent with a study showing that high GSE is associated with a better HRQOL [12]. Selfefficacy contributed significantly to predict the variation in all HRQOL dimensions among this sample, especially for the subscales physical well-being and self-perception. These scales explore levels of physical activity and energy, whether the adolescent feels well physically, and general feelings about how satisfied the adolescent feels about him/herself [43]. For adolescents who are victims of bullying, self-efficacy may mediate the negative effects of being bullied. A study from Greece showed that strengthening young persons' GSE can reduce the health consequences of being bullied [38]. GSE is a personal resource related to the belief that you have the competence to handle difficult or new tasks and situations [40]. An adolescent with a low score on the GSE belief scale may be more likely to set lower personal goals and to have lower self-esteem. In the context of bullying, the adolescent's poor self- esteem may affect his/her perception of their situation. Internal resources, such as increased self-efficacy, may be central to overcoming the victim role $[5,53]$.

Self-esteem and self-efficacy may be related concepts; however, self-esteem refers to the person's thoughts about their worth, whereas self-efficacy is about the person's judgments about their unique abilities to act and cope $[6,54]$. Self-perception, as used in the Kidscreen questionnaire, refers to how satisfied the adolescent feels about him/herself as well as his/her appearance [45].

According to Bandura $[7,55]$, self-efficacy is a concept that can change, such as through goal-setting counseling, motivation from others, and through education. One study reported that self-efficacy increased significantly for socially withdrawn schoolchildren after participating in an intervention to improve this measure
[56], which may indicate that self-efficacy is a resource for increasing the HRQOL among bullied children.

Our results highlight the importance of targeting selfefficacy beliefs as an intervention strategy with adolescents involved in bullying. Moreover, it indicates that improving self- efficacy and developing positive coping behaviours, could be effective in increasing adolescents HRQOL. School is an important setting for the promotion of social skills, and which may also enhance health. Adolescents spend most of their time in school, and the school setting is therefore a critical arena for interventions and social support.

\section{Strengths and limitations}

Potential limitations must be considered when interpreting our results. Because it was a cross-sectional study, it is not possible to make causal inferences. Adolescents who were absent on the day of the study did not participate and we cannot assess whether participants and nonparticipants differed in any respect. These results might be regarded as representative of adolescents in one region of Norway, but we do not know whether they generalize to the rest of the country. However, the school system in Norway is fairly homogeneous, so the findings should be similar for the same age group in other regions. We used two widely used questions from Olweus to measure bullying; however, these are just single items, and the variables were dichotomized to never being bullied/bully other, versus bully/being bullied once or twice or more during the last 3 months. It is left to be determined how well being bullied/bully other once or twice cover the criteria "over time" in the definition of the concept.

Strengths of the study include the relatively large sample of adolescents (overall response rate 74\%), which is considered satisfactory, and that we used well-validated questionnaires. We have studied the associations between GSE and bullying and HRQOL. In our discussion, we indicate that GSE may moderate the effect of bullying on HRQOL. However, this should be studied further by testing the mediating effects with a structural equation modelling approach.

\section{Conclusions}

In this cross-sectional study, we found that being bullied and bullying others were both associated with lower HRQOL, and that higher GSE scores were associated with better HRQOL in adolescents. Self-efficacy contributed significantly to predict variation in HRQOL dimensions and may mediate the negative association between bullying and HRQOL. Assessing HRQOL among adolescents allows us to discover threats to their well-being and to become more aware of vulnerable subgroups. The relationship between GSE and HRQOL indicates 
that self-efficacy might be a resource for increasing HRQOL among adolescents. School is important for children's social and emotional development, and an important arena for interventions. Our findings highlight the importance of targeting self-efficacy beliefs as an intervention strategy to improve GSE and HRQOL in adolescents involved in bullying. These findings need to be followed up in further studies; longitudinal studies could examine this relationship more thoroughly and determine the direction of the associations reported herein.

\section{Abbreviations \\ GSE: General self-efficacy; HRQOL: Health-related quality of life}

\section{Publisher's Note}

Springer Nature remains neutral with regard to jurisdictional claims in published maps and institutional affiliations.

\section{Acknowledgements}

We are grateful to the adolescents who participated in the study and to the teachers and school nurses who made the study possible.

\section{Authors' contributions}

$\mathrm{KH}$ designed the study, collected the data, participated in statistical analysis, and drafted the manuscript; SH served as the study's principal investigator, participated in the design and statistical analysis, and helped draft the manuscript; LGK participated in data collection and helped draft the manuscript; KAC performed the statistical analyses and helped draft the manuscript; all authors read and approved the final version of the manuscript.

\section{Funding}

Financial support for this project was made available through a grant from Oslo Metropolitan University (OsloMet), Faculty of Health.

\section{Availability of data and materials}

The datasets analyzed as part of the current study are available from the corresponding author upon reasonable request.

\section{Ethics approval and consent to participate}

The study was reviewed and approved by the Regional Research Ethics Committee of Norway (REK. Sør S-0643). All participants provided written informed consent. Consent to participate was obtained from the parents of children under the age of 16 years.

\section{Consent for publication}

Not applicable.

\section{Competing interests}

The authors declare that they have no competing interests.

\section{Author details}

${ }^{1}$ Faculty of Health- and Sport Sciences, University of Agder, P.O box 422, 4604 Kristiansand, Norway. ${ }^{2}$ Faculty of Health, OsloMet, Oslo Metropolitan University, P.O box 4, St Olavs Plass, 0130 Oslo, Norway. ${ }^{3}$ Faculty of Social Sciences, University of Oslo, P.O box 1084, Blindern, 0317 Oslo, Norway.

Received: 23 October 2018 Accepted: 5 June 2019

Published online: 14 June 2019

\section{References}

1. Langford R, Bonell C, Jones H, Pouliou T, Murphy S, Waters E, Komro K, Gibbs L, Magnus D, Campbell R. The World Health Organization's health promoting schools framework: a Cochrane systematic review and metaanalysis. BMC Public Health. 2015;15:130.

2. Ravens-Sieberer U, Herdman M, Devine J, Otto C, Bullinger M, Rose M, Klasen F. The European KIDSCREEN approach to measure quality of life and well-being in children: development, current application, and future advances. Qual Life Res. 2014;23(3):791-803.
3. Varni JW, Burwinkle TM, Lane MM. Health-related quality of life measurement in pediatric clinical practice: an appraisal and precept for future research and application. Health Qual Life Outcomes. 2005;3:34.

4. Petersen-Ewert C, Erhart M, Ravens-Sieberer U. Assessing health-related quality of life in European children and adolescents. Neurosci Biobehav Rev. 2011;35(8):1752-6.

5. Kvarme LG, Haraldstad K, Helseth S, Sorum R, Natvig GK. Associations between general self-efficacy and health-related quality of life among 1213-year-old school children: a cross-sectional survey. Health Qual Life Outcomes. 2009;7:85.

6. Bandura A. Self-efficacy: toward a unifying theory of behavioral change. Psychol Rev. 1977;84(2):191-215.

7. Bandura A, Cioffi D, Taylor CB, Brouillard ME. Perceived self-efficacy in coping with cognitive stressors and opioid activation. J Pers Soc Psychol. 1988;55(3):479-88.

8. Natvig GK, Albrektsen G, Qvarnstrom U. Associations between psychosocial factors and happiness among school adolescents. Int J Nurs Pract. 2003;9(3): $166-75$

9. Wang X, Zhang Y, Hui Z, Bai W, Terry PD, Ma M, Li Y, Cheng L, Gu W, Wang $M$. The mediating effect of regulatory emotional self-efficacy on the association between self-esteem and school bullying in middle school students: a cross-sectional study. Int J Environ Res Public Health. 2018;15(5).

10. Schwarzer R, Renner B. Social-cognitive predictors of health behavior: action self-efficacy and coping self-efficacy. Health Psychol. 2000;19(5):487-95.

11. Wilkins-Shurmer A, O'Callaghan MJ, Najman JM, Bor W, Williams GM, Anderson MJ. Association of bullying with adolescent health-related quality of life. J Paediatr Child Health. 2003;39(6):436-41.

12. Otto C, Haller AC, Klasen F, Holling H, Bullinger M, Ravens-Sieberer U. Risk and protective factors of health-related quality of life in children and adolescents: results of the longitudinal BELLA study. PLoS One. 2017;12(12): e0190363.

13. Allison $S$, Roeger $L$, Reinfeld-Kirkman N. Does school bullying affect adult health? Population survey of health-related quality of life and past victimization. Aus N Z J Psychiatry. 2009;43(12):1163-70.

14. Chester KL, Spencer NH, Whiting L, Brooks FM. Association between experiencing relational bullying and adolescent health-related quality of life. Journal School Health. 2017;87(11):865-72.

15. Fantaguzzi C, Allen E, Miners A, Christie D, Opondo C, Sadique Z, Fletcher A Grieve R, Bonell C, Viner RM, et al. Health-related quality of life associated with bullying and aggression: a cross-sectional study in English secondary schools. Eur J Health Econ. 2018;19(5):641-51.

16. Gonzalez-Cabrera J, Leon-Mejia A, Beranuy M, Gutierrez-Ortega M, AlvarezBardon A, Machimbarrena JM. Relationship between cyberbullying and health-related quality of life in a sample of children and adolescents. Qual Life Res. 2018.

17. Frisen A, Bjarnelind S. Health-related quality of life and bullying in adolescence. Acta Paediatr. 2010:99(4):597-603.

18. Modecki KL, Minchin J, Harbaugh AG, Guerra NG, Runions KC. Bullying prevalence across contexts: a meta-analysis measuring cyber and traditional bullying. J Adolesc Health. 2014;55(5):602-11.

19. Undheim AM, Sund AM. Prevalence of bullying and aggressive behavior and their relationship to mental health problems among 12- to 15-year-old Norwegian adolescents. Eur Child Adolesc Psychiatry. 2010;19(11):803-11.

20. Magklara K, Skapinakis P, Gkatsa T, Bellos S, Araya R, Stylianidis S, Mavreas V. Bullying behaviour in schools, socioeconomic position and psychiatric morbidity: a cross-sectional study in late adolescents in Greece. Child Adolesc Psychiatry Ment Health. 2012;6:8.

21. Analitis F, Velderman MK, Ravens-Sieberer U, Detmar S, Erhart M, Herdman M, Berra S, Alonso J, Rajmil L. Being bullied: associated factors in children and adolescents 8 to 18 years old in 11 European countries. Pediatrics. 2009;123(2):569-77.

22. Sigurdson JF, Undheim AM, Wallander JL, Lydersen S, Sund AM. The longterm effects of being bullied or a bully in adolescence on externalizing and internalizing mental health problems in adulthood. Child Adolesc Psychiatry Ment Health. 2015;9:42.

23. Sigurdson JF, Wallander J, Sund AM. Is involvement in school bullying associated with general health and psychosocial adjustment outcomes in adulthood? Child Abuse Negl. 2014;38(10):1607-17.

24. Brunstein Klomek A, Snir A, Apter A, Carli V, Wasserman C, Hadlaczky G, Hoven CW, Sarchiapone M, Balazs J, Bobes J, et al. Association between victimization by bullying and direct self injurious behavior among 
adolescence in Europe: a ten-country study. Eur Child Adolesc Psychiatry. 2016:25(11):1183-93.

25. Undheim AM, Wallander J, Sund AM. Coping strategies and associations with depression among 12- to 15-year-old Norwegian adolescents involved in bullying. J Nerv Ment Dis. 2016;204(4):274-9.

26. Olweus D. Bullying at school and later criminality: findings from three Swedish community samples of males. Crim Behav Ment Health. 2011; 21(2):151-6.

27. Wolke D, Copeland WE, Angold A, Costello EJ. Impact of bullying in childhood on adult health, wealth, crime, and social outcomes. Psychol Sci. 2013;24(10):1958-70.

28. Troop-Gordon W. Peer victimization in adolescence: the nature, progression, and consequences of being bullied within a developmental context. J Adolesc. 2017;55:116-28.

29. Troop-Gordon W, Sugimura N, Rudolph KD. Responses to interpersonal stress: normative changes across childhood and the impact of peer victimization. Child Dev. 2016.

30. Evans-Lacko S, Takizawa R, Brimblecombe N, King D, Knapp M, Maughan B, Arseneault L. Childhood bullying victimization is associated with use of mental health services over five decades: a longitudinal nationally representative cohort study. Psychol Med. 2017:47(1):127-35.

31. Lee KS, Vaillancourt T. Longitudinal associations among bullying by peers, disordered eating behavior, and symptoms of depression during adolescence. JAMA Psychiatry. 2018;75(6):605-12.

32. Waasdorp TE, Pas ET, Zablotsky B, Bradshaw CP. Ten-year trends in bullying and related attitudes among 4th- to 12th-graders. Pediatrics. 2017;139(6).

33. Lereya ST, Copeland WE, Zammit S, Wolke D. Bully/victims: a longitudinal, population-based cohort study of their mental health. Eur Child Adolesc Psychiatry. 2015;24(12):1461-71.

34. Copeland WE, Wolke D, Angold A, Costello EJ. Adult psychiatric outcomes of bullying and being bullied by peers in childhood and adolescence. JAMA Psychiatry. 2013;70(4):419-26.

35. Olweus D. School bullying: development and some important challenges. Annu Rev Clin Psychol. 2013;9:751-80.

36. Palermo TM, Valrie CR, Karlson CW. Family and parent influences on pediatric chronic pain: a developmental perspective. Am Psychol. 2014;69(2): $142-52$

37. Olweus D. Bullying at school: basic facts and effects of a school based intervention program. J Child Psychol Psychiatry. 1994;35(7):1171-90

38. Kokkinos CMPP, Tsolakidou I, Tzeliou E. Coping with bullying and victimisation among pre-adolescents: the moderating effect of self-efficacy. Emot Behav Diffic. 2015;20(2):205-22

39. Ystrom E, Niegel S, Klepp KI, Vollrath ME. The impact of maternal negative affectivity and general self-efficacy on breastfeeding: the Norwegian mother and child cohort study. J Pediatr. 2008;152(1):68-72.

40. Luszczynska A, Scholz U, Schwarzer R. The general self-efficacy scale: multicultural validation studies. J Psychol. 2005;139(5):439-57.

41. Solberg ME, Olweus D, Endresen IM. Bullies and victims at school: are they the same pupils? Br J Educ Psychol. 2007;77(Pt 2):441-64.

42. Haraldstad K, Christophersen KA, Eide H, Nativg GK, Helseth S. Health related quality of life in children and adolescents: reliability and validity of the Norwegian version of KIDSCREEN-52 questionnaire, a cross sectional study. Int J Nurs Stud. 2011:48(5):573-81.

43. Ravens-Sieberer U, Gosch A, Rajmil L, Erhart M, Bruil J, Power M, Duer W, Auquier P, Cloetta B, Czemy L, et al. The KIDSCREEN-52 quality of life measure for children and adolescents: psychometric results from a crosscultural survey in 13 European countries. Value Health. 2008;11(4):645-58.

44. Meade T, Dowswell E. Adolescents' health-related quality of life (HRQoL) changes over time: a three year longitudinal study. Health Qual Life Outcomes. 2016;14:14

45. The KIDSCREEN Group. The KIDSCREEN questionnaires, handbook. Berlin: PABST SCIENCE PUBLISHERS; 2006.

46. Juvonen J, Graham S. Bullying in schools: the power of bullies and the plight of victims. Annu Rev Psychol. 2014;65:159-85.

47. Nordhagen R, Nielsen A, Stigum H, Köhler L. Parental reported bullying amongNordic children: a population-based study. Child Care Health Dev. 2005;31(6):693-701.

48. Beckman L, Svensson M. The cost-effectiveness of the Olweus bullying prevention program: results from a modelling study. J Adolesc. 2015;45:127-37.

49. Svavarsdottir EK, Orlygsdottir B. Health-related quality of life in Icelandic school children. Scand J Caring Sci. 2006;20(2):209-15.
50. Undheim AM, Sund AM. School factors and the emergence of depressive symptoms among young Norwegian adolescents. Eur Child Adolesc Psychiatry. 2005;14(8):446-53.

51. Ravens-Sieberer U, Erhart M, Wille N, Wetzel R, Nickel J, Bullinger M. Generic health-related quality-of-life assessment in children and adolescents: methodological considerations. PharmacoEconomics. 2006;24(12):1199-220.

52. Meilstrup C, Ersboll AK, Nielsen L, Koushede V, Bendtsen P, Due P, Holstein BE. Emotional symptoms among adolescents: epidemiological analysis of individual-, classroom- and school-level factors. Eur J Pub Health. 2015;25(4):644-9.

53. Kvarme LG, Aabo LS, Saeteren B. From victim to taking control: support Group for Bullied Schoolchildren. J Sch Nurs. 2016;32(2):112-9.

54. Bandura A. The assessment and predictive generality of self-percepts of efficacy. J Behav Ther Exp Psychiatry. 1982;13(3):195-9.

55. Bandura A, Caprara GV, Barbaranelli C, Pastorelli C, Regalia C. Sociocognitive self-regulatory mechanisms governing transgressive behavior. J Pers Soc Psychol. 2001;80(1):125-35.

56. Kvarme LG, Helseth S, Sorum R, Luth-Hansen V, Haugland S, Natvig GK. The effect of a solution-focused approach to improve self-efficacy in socially withdrawn school children: a non-randomized controlled trial. Int J Nurs Stud. 2010:47(11):1389-96.

\section{Publisher's Note}

Springer Nature remains neutral with regard to jurisdictional claims in published maps and institutional affiliations.
Ready to submit your research? Choose BMC and benefit from:

- fast, convenient online submission

- thorough peer review by experienced researchers in your field

- rapid publication on acceptance

- support for research data, including large and complex data types

- gold Open Access which fosters wider collaboration and increased citations

- maximum visibility for your research: over $100 \mathrm{M}$ website views per year

At BMC, research is always in progress.

Learn more biomedcentral.com/submissions 